\title{
UNA OBRA ESCULTÓRICA INCLUYE VÍCTIMAS DE CAMPOS SOCIALES EXCLUYENTES. EL CASO DE LA MASACRE DE FORESTA, BUENOS AIRES (ARGENTINA)
}

\section{A sculpture that includes victims of exclusionary social fields. The case of the Slaughter of Floresta, Buenos Aires (Argentina)}

\author{
Alicia Irene Rebollar* \\ * Instituto de Altos Estudios Sociales, Universidad Nacional de San Martín (Argentina) \\ alicia_rebollar@hotmail.com
}

\section{Palabras clave \\ Víctimas \\ Terrorismo de Estado \\ Democracia \\ Monumento- \\ homenaje \\ Derechos Humanos}

\section{Keywords}

Victims

State terrorism

Democracy

Monument-tribute

Human Rights

\begin{abstract}
Resumen
A fines de diciembre de 2001 mueren tres jóvenes en el barrio porteño de Floresta en un caso de "gatillo fácil", conocido como la Masacre de Floresta. Se convocaron veinticuatro marchas para pedir justicia. Tras lograr la condena al victimario, el barrio se abocó a la construcción de un monumento-homenaje. En esta obra escultórica confluyeron víctimas disímiles: las víctimas del terrorismo de Estado, consagradas en el espacio público, con víctimas de represión estatal en democracia que luchaban por reconocimiento dentro del campo de los derechos humanos como víctimas de inseguridad. ¿Cómo fue posible unir a estas víctimas con visiones diferentes del pasado reciente en un mismo monumento-homenaje? Para dar respuesta a esa pregunta, se recurre al trabajo de campo cualitativo, especialmente entrevistas a los principales actores participantes en el proceso de creación, construcción, emplazamiento e inauguración de la obra escultórica. El análisis se apoya en autores cuyas teorías permiten evitar la naturalización de las categorías utilizadas. Desde una perspectiva procesual y relacional se muestra que, además de la represión estatal, la preeminencia de un punto de vista, entre los varios que integran el campo de los derechos humanos en la Argentina, fue un elemento fundamental para la concreción de una obra escultórica que reunió víctimas jerárquicamente disímiles.
\end{abstract}

\section{Abstract}

In late December 2001, three young people died in the neighborhood of Buenos Aires, Floresta, in a case of "easy trigger", known as the Slaughter of Floresta. Twenty-four marches had place to ask for justice. After the condemnation of the perpetrator, the neighborhood focused on the construction of a monument-tribute. Dissimilar victims came together In this sculptural work: victims of state terrorism, consecrated in the public space, along with victims of state repression in democracy who were fighting for recognition in the field of human rights as victims of insecurity. How was possible to unite these victims with different worldviews in the same monument-tribute? In order to answer this interrogation, qualitative fieldwork was used, mainly interviews with the main actors involved in the creation, construction, siting and inauguration of the sculptural work. The analysis is based on authors whose theories allow to avoiding the naturalization of the categories used. From a procedural and relational perspective, I show that, in addition to state repression, the preeminence of a point of view among those who integrate the field of human rights in Argentina was a fundamental element for the concretion of a sculptural work, which brought together hierarchically dissimilar victims.

Rebollar, A. I. (2017). Una obra escultórica incluye víctimas de campos sociales excluyentes. El caso de la Masacre de Floresta, Buenos Aires (Argentina). Papeles del CEIC, vol. 2017/1, papel 172, CEIC (Centro de Estudios sobre la Identidad Colectiva), UPV/EHU Press, http://dx.doi.org/10.1387/pceic.16969 


\section{INTRODUCCIÓN ${ }^{1}$}

El estallido de la crisis socioeconómica y política que se vivió en la Argentina durante 2001 y 2002 ofició de contexto propiciador del encuentro de los vecinos en el espacio público. Los últimos días de diciembre de 2001 estuvieron signados por movilizaciones populares, marchas, asambleas, cacerolazos y una fuerte represión policial. La novedad de la irrupción de los sectores medios en la protesta callejera tuvo su expresión más acabada en los llamados cacerolazos, palabra que ha pasado a simbolizar las formas específicas de movilización de estos sectores. La organización de asambleas barriales resultó otro de los hechos novedosos producidos en ese contexto de crisis, ya que constituyeron polos de participación política que dotaron de nuevo contenido a la política local en contextos urbanos.

En ese momento de movilización de la sociedad civil ocurrió un hecho de violencia policial que se conoce como Masacre de Floresta. El 29 de diciembre de 2001, tras manifestarse en el cacerolazo del barrio de Floresta, en la Ciudad Autónoma de Buenos Aires resultaron muertos Cristian Gómez, Maximiliano Tasca y Adrián Matassa en un caso de "gatillo fácil" 2 . Al día siguiente, un matutino vinculó el hecho directamente con la crisis del 2001 subtitulando: "La crisis del nuevo gobierno: cacerolazo de vecinos y represión en Floresta por el triple crimen"3. La Masacre activó la movilización de los vecinos a través de marchas, actos de denuncia y manifestaciones públicas. Durante el año 2002, la intensidad del reclamo no decayó: por los chicos de Floresta se hicieron 24 marchas. A varios meses de la tragedia, los vecinos, los familiares y los amigos de los jóvenes siguieron marchando y exigiendo que se realizase el juicio oral por la masacre. Finalmente, el acusado fue sentenciado en marzo de 2003 a cadena perpetua.

Luego de la sentencia el barrio siguió movilizado generando diversos proyectos sociales y culturales. Un integrante de la Asamblea Barrial de

\footnotetext{
${ }^{1}$ Este trabajo de investigación se inscribe en el proyecto "Empresas de memorialización del pasado reciente en la Argentina. Estado, activismo e institución de nuevas categorias y símbolos nacionales" dirigido por la Dra. V. Vecchioli en la Universidad Nacional de General Sarmiento (Argentina).

${ }^{2}$ La expresión "gatillo fácil" es la denominación de uso popular que refiere a hechos de violencia policial.

3 "Un policía retirado discutió con tres jóvenes y los mató a tiros", Diario Clarín, 30/12/2001. Disponible en: http://edant.clarin.com/diario/2001/12/30/p-01401.htm. Última consulta: 22/05/2015.
} 
Floresta recuerda esa época como una "usina de ideas", proponiéndose, entre otras, la construcción de un monumento-homenaje a las víctimas de la Masacre. Se convocó a concurso público y la obra escultórica ganadora fue emplazada en el emblemático predio conocido como El Corralón. El Corralón es un espacio físico ubicado en el mismo barrio de Floresta y que es reconocido como "lugar de memoria" (Jelin y Langland, 2003) de luchas sindicales en la década de 1960, de detenidos desaparecidos en la década siguiente, y del escobazo, una protesta barrial, en los años noventa.

Las víctimas de la Masacre de Floresta fueron catalogadas como víctimas de "gatillo fácil". La Coordinadora contra la Represión Policial e institucional (CORREPI) ${ }^{4}$ es la institución que ejerce la mayor representación de estas víctimas. Sin embargo, ni la CORREPI tomó este caso ni los familiares de las víctimas de Floresta se integraron a dicha organización. Al contrario, dos de las madres de las víctimas formalizaron, en 2004, la Asociación Madres del Dolor que pedía justicia para victimas en democracia de diversos hechos violentos: accidentes de tránsito, violación seguida de muerte, secuestro seguido de muerte, "gatillo fácil", muerte por inseguridad y violencia institucional. Si bien ambas agrupaciones trabajan por los derechos humanos de las víctimas de "gatillo fácil", adoptan posturas diferentes frente a la violencia de Estado, en especial la violencia policial. La CORREPI considera que el Estado, tras la última dictadura, ha mantenido "un aparato represivo directamente proporcional a los conflictos sociales que pudieran mover el escenario de estabilidad deseado para mantener la tranquilidad de la cadena capitalista" ${ }^{5}$. Así las muertes por "gatillo fácil" fueron entendidas, por esta organización, como producto de resabios de prácticas represivas propias del terrorismo de Estado. Mientras que la madre de una de las víctimas de "gatillo fácil" integrante de las Madres del Dolor expresaba: "nosotras guardamos respeto por la institución policial, la distinguimos de los policías que delinquen y se amparan en la institución

\footnotetext{
${ }^{4}$ El campo de protesta contra la violencia policial en la Argentina se fue gestando desde principios de los noventa con varios casos: "la masacre de Budge", "el caso Bulacio" y "el caso Schiavini". Esta organización es resultante de la confluencia de abogados con experiencia en el tema anti-represivo, familias de víctimas de "gatillo fácil" y grupos militantes. En esta organización, sus participantes se definen como "compañeros de lucha" (Pita, 2010: 44).

5 "El movimiento de derechos humanos y la conflictividad social". Correpi-Antirrepresivo, 01/04/1999. Disponible en: www.correpi.lahaine.org/? $p=310$. Última consulta: 17/02/2017.
} 
para permanecer impunes" (Entrevista personal, mayo de 2010). Así que esta asociación interpela al Estado por las muertes por "gatillo fácil" en su rol de proveedor de seguridad ciudadana. Estas diferentes visiones del Estado frente a las víctimas de "gatillo fácil" son disputadas dentro del campo de los derechos humanos ${ }^{6}$. Sin embargo, en este caso las vamos a encontrar integradas en una misma obra escultórica.

A pesar de las disputas entre estas organizaciones sobre la interpretación del rol del Estado, el monumento-homenaje consiguió reunir a víctimas del terrorismo de Estado, ya consagradas en el espacio público, con víctimas que sus familiares adjudicaban a hechos violentos en democracia y que buscaban reconocimiento estatal. ¿Cómo fue posible la confluencia de actores disímiles en un mismo monumentohomenaje? La pregunta debe ser entendida en una situación en la que, en palabras de Virginia Vecchioli, "las leyes de reparación, la nómina exhibida en un monumento suponen la institución de una frontera entre las víctimas y otras categorías que no alcanzaron el mismo éxito social" (2013: 24). Es decir que, "este proceso de oficialización, al tiempo que reconoce y legitima a algunos actores, demandas y principios de visión sobre el pasado reciente de la Argentina, produce el desconocimiento de otras categorías y puntos de vista" (ibídem). Justamente aquí está el problema a dirimir: mientras las víctimas del terrorismo de Estado estaban reconocidas y legitimadas, las víctimas de hechos violentos en democracia luchaban por ser reconocidas e integrarse al campo de los derechos humanos ${ }^{7}$. El monumento que describo aquí posibilitó la integración de ambas categorías en un mismo espacio simbólico, un hecho novedoso que merece el esfuerzo de analizar el proceso que lo hizo posible.

El objetivo de este artículo es, entonces, indagar en el proceso de construcción y emplazamiento del monumento-homenaje que posibilitó la unión de víctimas producidas en contextos históricos disímiles, y cuyos familiares militan en pos de causas a priori diferentes.

\footnotetext{
6 "Se trata de un campo en cuyo seno distintos actores luchan por establecer e imponer una definición legítima sobre los derechos humanos y sobre el pasado reciente $y$, al hacerlo, del lugar que ocupan en la escena pública actual" (Vecchioli, 2013: 26).

${ }^{7}$ Cuando se utilice la categoría víctima se está remitiendo a un sujeto político, "reconociendo que, en la actualidad, las personas participan de la vida pública no sólo a través de su inclusión en partidos y sindicatos sino también a partir de la creación de asociaciones civiles y movimientos sociales que se constituyen a partir del reclamo por los derechos de las víctimas" (Vecchioli, 2014a: 359).
} 
Para lograr este objetivo se ha recurrido al material recopilado entre 2010 y 2015 durante mi trabajo de campo con la Asociación Madres del Dolor. En la tarea se utilizaron las herramientas metodológicas propias de la antropología: observación participante, entrevistas en profundidad y conversaciones informales con las madres de las víctimas de la Masacre, con familiares de otras víctimas de "gatillo fácil", con integrantes de la Asociación Madres del Dolor, con integrantes de la Asamblea de Floresta y con las escultoras encargadas del monumento. Los datos obtenidos de primera mano se complementaron con la consulta de fuentes secundarias: diarios, documentos aportados por los actores, y páginas digitales de asociaciones del barrio de Floresta.

El texto comienza presentando el inquieto barrio de Floresta. Luego se mostrará quienes fueron las diferentes víctimas y sus diferentes "contextos de experiencia" (Cefaï, 2011) y se presentará la represión estatal como el hilo conductor, pero no suficiente, para aglutinar a las diferentes víctimas. Posteriormente se expondrán las posiciones que los actores movilizados manifestaron tener en relación a la política como forma de acción. En el siguiente acápite se abordarán las vicisitudes de la creación, construcción y emplazamiento del monumento visto como un "objeto de disputa" (Gugliemucci, 2011). Finalmente, se mostrará qué elementos permitieron la reunión en un mismo monumento de víctimas jerárquicamente disímiles y con puntos de vista diferentes en relación al pasado reciente.

\section{FLORESTA: UN BARRIO INQUIETO}

Como un barrio inquieto definió a Floresta la madre de una de las víctimas de la Masacre, y se debe a que el monumento que recuerda a los jóvenes muertos fue construido, gestionado y emplazado en el propio barrio por la intervención de sus vecinos: asambleístas, familiares de víctimas, artistas, agentes estatales de las Secretarías de Educación y de Derechos Humanos del gobierno porteño de Aníbal Ibarra ${ }^{8}$. Y, además, porque el lugar elegido para emplazar el monumento fue la Plaza de la Victoria ubicada dentro del emblemático espacio barrial conocido como El Corralón. La historia de este espacio se remonta a fines del siglo XIX cuando el barrio comenzaba a urbanizarse. Con el

\footnotetext{
${ }^{8}$ Aníbal lbarra fue Jefe de Gobierno de la Ciudad de Buenos Aires entre agosto de 2000 y marzo de 2006.
} 
crecimiento de la ciudad se presentaba el problema del saneamiento ambiental, por lo cual en 1911 una ordenanza autorizó al gobierno municipal la adquisición de un terreno ubicado en Floresta que se destinó a la instalación del corralón de limpieza. En principio sirvió como depósito de adoquines y otros materiales de pavimentación. Tras unos años, comenzó a albergar las chatas que servían para recolectar la basura y los carros que usaban los barrenderos. Este movimiento sumado a la existencia de casi cien caballos y mulas que tiraban de los carros hacía necesaria la presencia de herreros, cuidadores de caballerizas y de un veterinario de forma permanente. Además, se realizaban tareas de maestranza y de atención de las oficinas (Sampaolo, 2009). Es decir, en los comienzos del barrio, en las primeras décadas del siglo XX, El Corralón constituyó una fuente de empleo.

A mediados de 1940, los vecinos reclamaron el traslado de las funciones de limpieza a un lugar más apartado de la ciudad por razones de higiene. Recién en 1965 el intendente de la Ciudad de Buenos Aires resolvió que se estudiase la posibilidad de trasladar la basura a un predio en los límites con la provincia de Buenos Aires, y la creación en ese espacio de una plaza pública con un patio de juegos infantiles. Actualmente, en el barrio sigue vigente el recuerdo de una gran huelga de los trabajadores de la basura en 1962. Como producto del conflicto, grandes cantidades de desperdicios quedaron acumuladas en las calles del barrio de Floresta y del resto de la ciudad. Desde ese momento una empresa privada se hizo cargo de una parte de los servicios y contrató el personal de forma precaria privándolos de beneficios sociales (ibídem). Como síntesis la publicación digital "La Floresta" señaló que: "El lugar no fue ajeno a las luchas sociales. Hubo huelgas duras en el comienzo de los años '60. El predio y su gente vieron aparecer a los primeros movimientos que buscaban privatizar el tema de la basura"'.

En 1973 varios jóvenes de la organización Juventud Peronista emprendieron la tarea de conseguir "la municipalización de los recolectores". Para ello comenzaron a trabajar en El Corralón disputando posteriormente las elecciones internas para elegir delegados, que como en otros gremios enfrentaron a la Juventud Trabajadora Peronista (JTP) y a la Juventud Sindical Peronista (JSP) (ibídem). Más tarde, durante la segunda mitad de la década de los

9 Disponible en: http://www.la-floresta.com.ar/2008/julio/21.htm. Última consulta: 19/05/2015. 
setenta, la página digital "La Floresta" daba cuenta de que "trabajaron en él, militantes detenidos desaparecidos por la última dictadura"10.

Aquel reclamo de los vecinos al municipio, en la década de 1940, por traslado de las funciones de limpieza hacia las afueras de la ciudad, fue replicado en 1997 con "el escobazo", un corte de la Avenida Gaona en el barrio de Floresta, que convocó a los vecinos que pretendieron barrer con sus escobas la suciedad que simbolizaba El Corralón aún en funcionamiento. En el año 2000 la Legislatura porteña sancionó el nuevo Código de Planeamiento Urbano. Con la promulgación de la ley 449, cuyos artículos 117 y 118 determinaban el cambio de uso del suelo, la manzana pasó a estar zonificada como Urbanización Parque salvo un $20 \%$ de su superficie, sobre la calle Morón, que fue destinada al guardado de equipamiento comunitario. De manera que El Corralón, símbolo de luchas sindicales y de protestas barriales, comenzaba su transformación producto de un trabajo conjunto entre los vecinos y el Gobierno de la Ciudad de Buenos Aires. El resultado fue un proyecto integral de área verde que contemplaba la construcción de una plaza y una escuela de enseñanza media, así como la puesta en valor y preservación de la casona histórica de El Corralón para su funcionamiento como centro cultural.

En 2001 se inauguraba la pequeña Plaza de la Victoria con un paseo de juegos, mientras que el resto de la manzana seguía en parte abandonada como un basural y otra seguía ocupada por una empresa privada de transformación de residuos. Tres años más tarde este lugar fue el elegido para emplazar el monumento por la Masacre ${ }^{11}$. La obra escultórica fue, en efecto, clave para continuar un desarrollo urbanístico que estaba aún a medias. Así, con la llegada del monumento se logró impulsar la construcción de la escuela de enseñanza media, el jardín maternal y la recuperación para uso comunitario de los galpones históricos. En este sentido, Vecchioli señala que "el espacio, y no solo el tiempo, también aparece organizado, clasificado y jerarquizado según los hitos considerados relevantes al interior de [un] mundo de agentes y relaciones" (2014c: 73). De manera que podemos pensar en un mundo de

\footnotetext{
${ }^{10}$ Disponible en: http://www.la-floresta.com.ar/2015/abril/18.htm. Última consulta: 19/05/2015.

${ }^{11}$ Un caso similar encontramos en el emplazamiento del Parque de la Memoria en la costa del río de La Plata que se insertó en programas de reforma de un espacio urbano marginal y abandonado al ser intervenido para convertirlo en espacio de memoria (Vecchioli, 2014b).
} 
agentes y relaciones que, con el emplazamiento de un sitio de memoria, secundariamente logró concretar un proyecto urbano. Pero además, permitió la extraña confluencia en un mismo monumento del recuerdo de luchas sindicales y barriales, el homenaje a los detenidos desaparecidos por el terrorismo de Estado, a las víctimas de los sucesos del 19 y 20 de diciembre de $2001^{12}$, y a las víctimas de la Masacre de Floresta. De alguna manera, se generó un proceso que logró trazar una línea de continuidad entre víctimas que ocupaban lugares diferenciales en la "jerarquía de la desdicha" (Agier, 2008: 81).

\section{QUIÉNES SON LAS VÍCTIMAS QUE CONFLUYERON EN EL MONUMENTO}

\subsection{Las víctimas del terrorismo de Estado}

En el paredón sobre avenida Gaona de El Corralón están pintadas tres siluetas que representan a los detenidos desaparecidos, Julio Goitia, Néstor Sanmartino y Mauricio Silva. A Sanmartino lo secuestraron en su domicilio junto a su esposa el 6 de mayo de 1977, ese mismo día se Ilevaron a Goitia de El Corralón, mientras que al sacerdote Silva lo secuestraron mientras barría las calles del barrio el 14 de junio de 1977. También sobre el portón de ingreso se puede ver un cartel en el que figuran los nombres de quince vecinos del barrio detenidos desaparecidos. Aunque, entre los vecinos le adjudican al barrio de Floresta la cantidad de 3.000 desaparecidos, esa cifra está posiblemente gestada en relación a la existencia en el barrio de dos ex-Centros Clandestinos de Detención (CCD): el Olimpo y Automotores Orletti. Estas víctimas del terrorismo de Estado están representadas en el monumento, según lo describe una de las escultoras, "sobre un zócalo en hierro en el que descansan formas escultóricas, de cuerpos, como restos de gente que ha muerto para que nosotros vivamos y tengamos un país mejor" ${ }^{13}$. De manera que estas víctimas son presentadas a través

\footnotetext{
${ }^{12}$ Durante el mes de diciembre de 2001 se sucedieron movilizaciones populares, marchas, asambleas, y cacerolazos. La tensión social y política creció de tal manera que el 19 de diciembre el entonces presidente Fernando de la Rúa decretó el estado de sitio en todo el territorio nacional. A pesar de estas medidas, los manifestantes no dejaron de concentrarse y siguieron ocupando las calles. El 20 de diciembre, tras una violenta represión, perdieron la vida 39 personas en distintos puntos del país.

${ }^{13}$ Fragmento extraído de un folleto gráfico que circuló en el barrio en el año 2004 durante la ejecución de la obra escultórica. Alli se invitaba a los vecinos del barrio a visitar el Centro
} 
de un relato heroico del cual son protagonistas. Para el caso de los sacerdotes víctimas de la represión estatal en los años setenta cabe adjudicarles la adhesión a una "ética sacrificial" tal cual la describe María Soledad Catoggio (2011). Mientras que la figura del héroe esta "indiscutiblemente asociada a la lucha armada" dentro del paradigma militar de "vencer o morir" (ibídem), la figura del mártir hace posible comprender la forma heroica por fuera de las caracteristicas del modelo tradicional de héroe moderno y así otorgar sentido a otras formas de militancia político-religiosas de la época. Entre los sacerdotes que lucharon por la "liberación de los pobres" (ibídem), pocos consideraron que el camino era la lucha armada, profundizando prioritariamente la condición religiosa. Dentro de la fe cristiana el martirio es vivido como un "privilegio", que a su vez, es entendido como un triunfo, "es el privilegio de unos pocos 'elegidos' a los ojos de Dios y 'reconocidos' entre los hombres" (ibídem: 105). El camino seguido se encontraba dentro de un amplio arco de posibles destinatarios del sacrificio: los jóvenes, los obreros, los pobres, entre otros, y el lugar social podía ser el barrio marginal, la fábrica, o la comunidad. Para el sacerdote Mauricio Silva, El Corralón fue el lugar elegido para ponerse al servicio de los pobres.

De modo que las víctimas del terrorismo de Estado fueron investidas por un prestigio otorgado por el relato heroico, por la gesta épica de sus familiares y ahora por la figura del martirio. En este sentido, Gabriel Gatti propone que la categoría detenido desaparecido posee "Ias credenciales adecuadas" para ubicarse en los primeros lugares de la "jerarquía de la desdicha" poniendo en juego la identidad del individuo (2011).

\subsection{Las víctimas en democracia}

Las víctimas del 19 y 20 de diciembre de 2001 fueron producto de la represión policial dentro de un período democrático. Estas víctimas no fueron identificadas en el monumento y tampoco fueron nombradas por las escultoras cuando describieron su obra, solo se hicieron presentes subrepticiamente con la inclusión en una placa al pie del monumento: "Sucesos 2001". Así los episodios violentos y las consecuentes muertes en diciembre del 2001 quedaron

de Formación Profesional, donde se realizaba la construcción, y ver a las escultoras junto a los estudiantes del taller de herrería durante el proceso de trabajo. 
indisolublemente unidos a la Masacre de Floresta y al terrorismo de Estado.

Días después de esas muertes, el sábado 29 de diciembre de 2001, la convulsión social continuaba; un grupo de policías comenzó a discutir con manifestantes ante lo que uno de estos últimos interpeló: "nosotros somos el pueblo, igual que ustedes, no entiendo por qué el otro día nos mataron como a perros. Si nosotros peleamos por ustedes también, no entiendo por qué nos reprimen" (Schuster et al., 2002: 45; resaltado de la autora). Tras el lanzamiento de gases lacrimógenos por parte de la policía, "algunos manifestantes se enfrentaron con dos policías, los patearon y les robaron el arma a uno de los uniformados." (ibídem: 45). En otro punto de la ciudad tres jóvenes que regresaban de participar del cacerolazo miraban la televisión en un maxi-kiosco del barrio de Floresta. Las imágenes televisivas reprodujeron lo que estaba aconteciendo en Plaza de Mayo, uno de los jóvenes hizo un comentario acerca de los policías que fueron golpeados por los manifestantes: "¡Está bien! Es lo mismo que hicieron ustedes la semana pasada!"14. En la mesa ubicada detrás de los jóvenes, un hombre de civil escuchaba la conversación, era suboficial retirado de la Policía Federal que trabajaba en la seguridad del lugar, quien se levantó y los acribilló. Según la empleada del maxi-kiosco, testigo del hecho, el ex policía gritó: ¡Basta!; y a continuación "les disparó y se los llevó a la rastra como si fueran animales" 15 .

Años más tarde, Silvia, la madre de una de las víctimas de la Masacre de Floresta, reflexionaba de esta manera:

...en 1976 yo estaba embarazada de Maxi, en marzo el mes terrible [el mes del golpe de Estado], yo era una mujer feliz. El 4 de agosto nace mi hijo y luego un represor, en el año 2001 y en democracia, se llevó su vida. Me siento una madre de la democracia pero mi vida también la destruyó un represor. ${ }^{16}$

\footnotetext{
14 "Un policía retirado discutió con tres jóvenes y los mató a tiros", Diario Clarín, 30/12/2001. Disponible en: http://edant.clarin.com/diario/2001/12/30/p-01401.htm. Última consulta: 22/05/2015

${ }_{15}$ Disponible en: http://argentina.indymedia.org/news/2002/12/72194.php. Última consulta: 25/09/2014. El resaltado es de la autora.

${ }^{16}$ Fragmento extraído de: "El Olimpo y Orletti para el barrio", 21/03/2004. Disponible en: www.argentina.indymedia.org/news/2004/03/184648.php. Última consulta: 19/08/2014. Resaltado de la autora.
} 
Con su testimonio Silvia daba cuenta del raro lugar que ocupaban las madres de los jóvenes de la Masacre de Floresta: ella era una "madre de la democracia", pero su hijo y los otros dos jóvenes se habían convertido en víctimas de un represor. Sin embargo, a las víctimas en democracia no las reviste el heroísmo, ni la épica ni el sacrificio con que sí cuentan las víctimas del terrorismo de Estado. Por el contrario, las muertes de las víctimas por la represión estatal en democracia fueron representadas por sus familiares o amigos con expresiones como: "los mataron como perros" o "los mató y arrastró como animales". María Victoria Pita aborda esta forma de morir en el campo de las víctimas de "gatillo fácil", centrándose en la CORREPI (2010). En su análisis, Pita muestra que la expresión "morir como un perro" refiere al tratamiento dado a la víctima en tanto no persona o no humano y que la ubica en un lugar fuera de lo social. Esta deshumanización de las víctimas las despoja de cualquier derecho y las convierte en un cuerpo sobre el que puede ejercerse la violencia, las transforma en 'seres matables' (ibídem: 22).

Ludmila Da Silva Catela aborda este fenómeno de la deshumanización en su trabajo con indigenas, campesinos y obreros en el norte de la Argentina (2011). Aquellos torturados o desaparecidos indígenas, campesinos $u$ obreros bajo el terrorismo de Estado, no fueron relacionados ni con el heroísmo ni con el martirio, sino que la violencia recibida se identificaba utilizando "metáforas de animalización de los cuerpos" (ibídem: 115). De tal modo que, no solo quedaban afuera del universo de las víctimas de terrorismo de Estado, sino que sus memorias solo fueron transmitidas oralmente dentro de los límites de su comunidad sin ganar reconocimiento público (ibídem). Así, podemos afirmar que dentro de las víctimas del terrorismo de Estado también opera la "jerarquía de la desdicha".

Algunos familiares de aquellos que fueron "muertos como perros" se proponen realizar un trabajo simbólico de "restitución de humanidad". Para ello, apelan a prácticas recordatorias, a la denuncia pública, y a formas de inscribir la identidad del muerto: epitafios, pancartas, entierros, etc. (Pita, 2010). En este sentido, Gatti propone que otorgar a un muerto la categoría de víctima lo ubica en el lugar necesario para definir la humanidad (2011), a lo que podemos agregar que también le restituye una humanidad arrebatada en la forma de morir, en la tortura o en la desaparición. Para Gatti la víctima "señala el borde último, la frontera de lo humano" (ibídem: 525), es una figura que puede definirse 
como "casi el contrasujeto del viejo sujeto humanista e ilustrado" (ibídem). De tal modo que "la víctima, humano en (el) extremo, hace posible lo humano mismo" (ibídem).

Dentro del repertorio de acción de quienes pedían justicia por las víctimas de Floresta la construcción de un monumento como forma de "restitución de humanidad" era una posibilidad. Sin embargo, algunas voces se alzaron en contra de la realización del homenaje. Durante la entrevista a una de las escultoras, ésta comentó que algunos vecinos se oponían a la ejecución de la obra al preguntarse: "por qué hacer tanto por unos chicos que ni siquiera eran militantes" (Entrevista personal, julio de 2015). Para sostener el esfuerzo colectivo necesario para emprender la realización del monumento fue necesario, entonces, investirlos de alguna cualidad heroica. En este sentido, se entienden las palabras de la escultora que argumentó a quiénes se oponían: "ellos fueron asesinados por expresarse en defensa de los muertos del 19 y 20 de diciembre" (Entrevista personal, julio de 2015). Con ello, situaba a estas víctimas dentro de un proceso más amplio de reclamación ante un Estado fracasado, que había abandonado su rol de proveedor de seguridad a sus ciudadanos. Así, las 24 marchas organizadas por los vecinos del barrio de Floresta pidiendo Justicia por los jóvenes muertos y la consecuente condena ejemplar al homicida, convirtieron la movilización en una gesta popular de ribetes épicos que, sin duda, justificaba la construcción de un monumento.

\section{3. ¿Fue la represión estatal el aglutinante?}

¿Cómo se logró unir en un mismo monumento a víctimas jerárquicamente disímiles: víctimas de terrorismo de Estado y víctimas en democracia? Todas estas muertes fueron producto de la represión del Estado, unas en periodos dictatoriales otras en democracia. Aunque el victimario de la Masacre de Floresta era un ex-policía, se lo consideraba un "represor" dado que en el momento de la tragedia contaba con sesenta y un años y, por lo tanto, integró la fuerza policial en la época de la dictadura. De esta manera, su reacción se enmarcó rápidamente dentro de conductas autoritarias y represivas adquiridas en el ejercicio de la profesión en aquella época. Fue como si a la hora de condenar al responsable, el tiempo no hubiera pasado. Esta suspensión del paso del tiempo es entendida por Katherine Verdery como una "reconfiguración del tiempo" (1999) cuyas implicaciones afectan, por ejemplo, a las 
responsabilidades y a las decisiones acerca de penas y compensaciones. De tal modo que por medio de un salto temporal, se pudo establecer una línea de continuidad entre la represión estatal de la época de la dictadura y la represión policial en democracia casi treinta años más tarde.

Esta línea temporal sin discontinuidades ni rupturas entre la represión de la década de 1970 y la actual represión a manos de la policía se replicaba en los dichos de la madre de una víctima de "gatillo fácil":
considero que los crímenes de ayer [los de la dictadura] están conectados con los crímenes de hoy [en democracia], son prácticas que quedaron en las fuerzas de seguridad. (Entrevista personal en la Secretaria de Derechos Humanos del Gobierno de la Ciudad de Buenos Aires donde ejerce funciones, septiembre de 2010)

En un sentido similar se expresa una de las escultoras del monumento: "no es casual que el asesino haya sido producto de la dictadura" (Entrevista personal, julio de 2015).

Sin embargo, los contextos en que los que la represión fue ejercida no son iguales $y$, por lo tanto, produjeron víctimas diferentes. Daniel Cefaï recomienda atender a los "contextos de experiencia" de los actores que dan sentido a las categorías que organizan el mundo, y así poder comprender las variaciones del sentido otorgado a una determinada categoría (2011). Así que, como vimos, las víctimas de terrorismo de Estado en la década de 1970 por la vía del derrotero de la tortura y la desaparición física fueron inscriptas dentro de un relato heroico, de una gesta épica y sacrificial. En 2001 las víctimas de la represión estatal habían salido a las calles reclamando por la falta de trabajo y la extrema situación económica. Para 2004, pasados casi treinta años del golpe militar, los reclamos de la ciudadanía eran otros, cuando se manifestaba en las calles estaba interpelando al Estado en su rol de proveedor de seguridad ciudadana. Si bien en el caso de las víctimas de Floresta el victimario fue considerado un represor de la dictadura militar, sus familiares se manifestaron como víctimas en democracia, un universo en gestación que comenzaba a luchar por instalar sus reclamos en la agenda estatal de los derechos humanos.

Si en un primer momento la represión estatal aparece como el factor aglutinante que posibilitó la unión de diferentes víctimas en el monumento a la Masacre de Floresta, podemos preguntarnos: ¿es 
suficiente la confluencia de una práctica represiva ligada al terrorismo de Estado para que víctimas en disputa dentro del campo de los derechos humanos se unan para la realización de un monumentohomenaje? ¿Qué otros elementos posibilitaron la reunión de víctimas consagradas con víctimas que luchan por su reconocimiento en un mismo "lugar de memoria"?

\section{LOS ACTORES MOVILIZADOS Y LA POLÍTICA}

\subsection{Los asambleístas y la política}

El inquieto barrio de Floresta al calor de la crisis económica y social del 2001 creó su propia asamblea barrial. Esos años se caracterizaron por el "que se vayan todos" 17 y junto a los cacerolazos aparecieron las asambleas barriales que de alguna manera asumieron la representación política. Estas agrupaciones, que en principio se reunieron para paliar las necesidades de los vecinos del barrio, organizando ollas populares, merenderos y comedores, posteriormente se desarrollaron como espacios de participación y discusión de inquietudes políticas.

Cuando ocurrió la Masacre de Floresta, la Asamblea del barrio cumplió un rol importante en la organización de las 24 marchas para pedir justicia por los jóvenes. Estas movilizaciones se caracterizaron por la falta de identificaciones político-partidarias, las únicas filiaciones que pudieron individualizarse fueron las camisetas del club de futbol All Boys, al que pertenecían las tres víctimas; además, se pudieron ver las pancartas de la murga del club, una bandera con la inscripción Justicia y otras banderas que identificaban a las asambleas barriales. Los jóvenes amigos de las víctimas vestían remeras blancas con la foto de los chicos estampadas en el pecho.

La ausencia de estandartes político-partidarios en las marchas de Floresta y la presencia de banderas alusivas a las asambleas barriales daban cuenta de que la lucha por la representación política había sido transitoriamente ganada por los grupos de pertenencia barrial que se solidarizaban con los familiares. En este sentido Daniel Gaxie sostiene que las marchas en las calles son una ocasión privilegiada para que un

\footnotetext{
17 "Qué se vayan todos" fue el lema bajo el cual se movilizó la población durante la revuelta popular generalizada durante la crisis del 2001 en la Argentina. La consigna expresaba la crisis de representatividad y el desencanto de la población respecto de sus dirigentes, exigiendo la renuncia masiva del gobierno.
} 
grupo se "manifieste manifestando" como forma de mostrar su existencia social (2004: 137). Esta puesta en escena se orienta a mostrar que se ha respondido al llamado de quienes se movilizaron tras un problema social, quienes desfilan a la cabeza del cortejo llevan sus estandartes representativos y así los "problemas sociales" se constituyen en "apuestas políticas" (ibídem).

Una de las asambleístas, de profesión socióloga, explica la importancia de trabajar en las organizaciones barriales desde un lenguaje académico:

Trabajar colectivamente la memoria (...) implica apropiarse de las reivindicaciones de justicia, reconstruir identidades e implementar estrategias sociales que instalen en el tiempo nuevas prácticas y acciones transformadoras de lo social, cultural, jurídico y político. (Entrevista personal, junio de 2015)

Otra asambleísta, que ejercía su profesión de docente y con anterioridad a la formación de la Asamblea de Floresta realizaba actividades de sindicalista en los Sindicatos Unidos de Trabajadores de la Educación (SUTE), extendió su militancia al barrio a partir de la Masacre. Pero, no fue hasta 2004 que su compromiso con las políticas de derechos humanos tornó a un activismo más partidario: "con la llegada de Néstor Kirchner, sentí que todo lo que veníamos haciendo el gobierno lo tomaba" (Entrevista personal, junio de 2015). En este sentido, a los asambleístas con militancias políticas o gremiales reconocidas, el tiempo del "que se vayan todos" les permitió poner en juego sus capacidades políticas para acompañar proyectos y posibilitar su concreción dentro de sus comunidades. Y además, muchos de ellos acompañaron las políticas de memoria, de los derechos humanos promovidas desde el Estado.

Cuando llegó a la Asamblea el proyecto de un artista plástico del barrio en memoria de la Masacre, a los asambleístas les pareció buena la idea realizar una obra de arte para recordar la tragedia. Pero las madres de las víctimas expresaron que ese proyecto "no les gustó", desde la Asamblea propusieron un concurso al que titularon "Crear para resistir". Esta constituyó otra forma de consumar sus propuestas políticas.

\subsection{Los familiares de las víctimas y la política}

A las marchas promovidas por la Asamblea de Floresta se sumaron familiares de víctimas de diversos delitos solidarizándose con las madres 
de la Masacre. En estas marchas, que se extendieron por más de un año, se comenzó a ensamblar el grupo que, años más tarde, se formalizaría como la Asociación Madres del Dolor. Este grupo, que se fue conociendo marchando por las calles, y golpeando las puertas de jueces y autoridades estatales pidiendo justicia, no dudó en expresar: "si bien nos diferenciamos, tomamos el ejemplo de las Madres de Plaza de Mayo. En el momento que salimos a la calle y reclamamos estamos haciendo derechos humanos, que la sociedad vea las víctimas en democracia" ${ }^{18}$.

En esos años, las Madres del Dolor tomaron distancia del reclamo por los derechos humanos de las víctimas del terrorismo de Estado. En conversaciones informales durante el trabajo de campo, las integrantes de la asociación se declaraban "apolíticas" y luchaban por sus propios derechos identificándose como "víctimas de la inseguridad", o preguntando: "¿los derechos de nuestros hijos dónde están?". A pesar de su distanciamiento, la apropiación que hicieron estos nuevos grupos de símbolos y estrategias creadas durante la década de 1970 estableció de alguna manera lazos y continuidades con la represión del pasado y con las organizaciones de derechos humanos (Da Silva Catela, 2014).

Las manifestaciones públicas de los familiares movilizados tuvieron efectos políticos en el espacio de la justicia. Una de las integrantes de la asociación, madre de una de las víctimas, expresó que gracias a las marchas durante el juicio los jueces:

sentian la respiración de la gente sobre sus nucas. En el juicio dudaban, se miraban (...) pero al fin fue condenado. Ellos tenian mucho miedo al estallido social (Entrevista personal, junio de 2010)

Sin embargo, a pesar de los efectos políticos que las marchas produjeron, una asambleista recuerda que:

en la primera de las marchas de Floresta, uno de los familiares de los chicos muertos echó a una de las Madres de Plaza de Mayo que se había unido a la marcha social (Entrevista personal, julio de 2015)

A continuación y como respuesta a la pregunta de por qué la echaron, la asambleísta contestó:

\footnotetext{
${ }^{18}$ Testimonio obtenido por la autora durante el trabajo de campo que fundamentó su tesis de graduación (Rebollar, 2014).
} 
hay que ver que en esos días se negaba la política, nadie se identificaba políticamente, las Madres de Plaza de Mayo se asociaban a una lucha política, en esos días nadie pensaba que la muerte de los chicos tuviera que ver con la política. (Entrevista personal, julio de 2015)

Ahora bien, ¿cómo entender las contradicciones de grupos que se declaraban ajenos a la política, que no se pensaban como gestores de lo político y que, sin embargo, su accionar generaba efectos tanto en los ámbitos judiciales, como legislativos y ejecutivos? Si bien podemos pensar que el descrédito de la política en aquellos tiempos del "que se vayan todos" justificaba el distanciamiento, ésta no parece una explicación suficiente. Siguiendo el trabajo de Diego Zenobi en torno al caso de Cromañon (2014), una tragedia ocurrida en 2004, una parte de los padres de las víctimas pedía que no se politizara el pedido de justicia, muy similar a lo que pedían las Madres del Dolor, y veía en los políticos profesionales, en los militantes y en los familiares politizados un riesgo, oponiéndose, con ello, a reconocer el carácter político de la demanda a partir de una supuesta oposición entre la "familia" y la "política". Por el contrario, otro grupo de familiares de víctimas de Cromañon que "entendía de política" (ibídem: 178), veía en ella una vía para obtener justicia por la muerte de sus hijos. Para este grupo el pedido de justicia implicaba marchar, escrachar, y además, reunirse con legisladores y políticos utilizando los códigos propios de los ámbitos en que estos actores accionan. Es decir, que éstos padres no consideraban la política y sus expresiones necesariamente en términos negativos, más bien el tema era el uso que se hacía de la política.

Entonces, lo que para una parte de los familiares de Crogmanon era "hacer política" (Zenobi, 2014) - poner en juego las trayectorias militantes, mover contactos personales, mover hilos, escuchar consejos, etc.- para las Madres del Dolor era luchar por conseguir "justicia por los hijos". Mientras, para los primeros la capacidad de "operar" junto a políticos y congresales había sido adquirida en abandonadas trayectorias gremiales o político partidaria, las Madres del Dolor apelaron la experiencia adquirida integrando algún voluntariado, a todas las relaciones personales adquiridas en sus trayectorias laborales, a sus contactos familiares y de amistad para acercarse a legisladores o agentes del poder ejecutivo. Pero también se pudo ver que estas activaciones no fueron suficientes para mantener vigente la lucha: a los 
"saberes previos"19 a la tragedia debieron sumar el aprendizaje de "competencias" que les permitieron construir exitosamente una "denuncia pública" (Boltanski, 1990) ${ }^{20}$. Para 2010 las Madres del Dolor habían logrado un lugar consolidado en el universo de los familiares de víctimas, y seguian manifestándose ajenas a la política. Al mismo tiempo reconocían que por esta postura, otros familiares de víctimas, las trataban de "tibias". Sin embargo, ellas defendian su posición presentándose como "punzantes como un tábano" y "siempre manejándose con respeto". Una estrategia que les abrió las puertas de despachos de jueces, legisladores y de la Casa Rosada.

\section{LAS VICISITUDES DE CREAR Y CONSTRUIR EL MONUMENTO}

\subsection{El concurso público "Crear para resistir"}

El lugar elegido para realizar el concurso fue la Escuela República del Perú, la primera escuela primaria estatal de la zona y lindera a El Corralón, allí se expusieron aproximadamente cincuenta maquetas. La directora de la escuela facilitó las instalaciones para el desarrollo del concurso; de ella dirian, tanto asambleístas como escultoras, que era una persona "comprometida, incluso militante, con los derechos humanos". La convocatoria al evento fue multitudinaria, una de las escultoras recuerda que "el día del concurso había cerca de dos mil personas, entre familiares, alumnos y vecinos". Para los asambleístas el evento fue convocante porque "la Asamblea se hizo eco de una necesidad del barrio, la idea surge de los familiares, de los vecinos y de los amigos de las víctimas". Sin embargo, no todo el barrio de Floresta estaba de acuerdo con la realización del monumento, la colaboración de algunos funcionarios del Estado con la Asamblea había despertado algunas críticas: "los amigos [de las víctimas] estaban negados al monumento, sentian desconfianza y decian que era una utilización política" (Entrevista personal a una asambleísta, julio de 2015). Otras voces ponían en cuestión la eficacia de emplazar un monumento como homenaje, temían poner en riesgo la movilización y la organización de

\footnotetext{
${ }^{19}$ Tal y como explica Benjamín Tejerina (2010), el activista aporta a la organización no solo recursos materiales y de formación profesional y práctica, sino que también incorpora su red de relaciones personales; estos "saberes previos" y relaciones pueden haberse gestado dentro de organizaciones.

${ }^{20}$ Sobre la importancia de la adquisición de capacidades competentes para la construcción de una denuncia pública, ver un estudio de caso en Rebollar (2016).
} 
tantos vecinos que habían "despertado a la militancia" a partir de la tragedia. Un asambleísta expresó que "un monumento sería congelar la memoria" (Entrevista personal, julio de 2015). Ahora bien, las oposiciones no tuvieron la suficiente fuerza como para impedir que el concurso siguiera adelante.

Las madres de las víctimas recuerdan las maquetas presentadas:

Había muchísimas, las iba viendo una por una, algunas me parecieron muy fuertes, muy dolorosas, y pensaba por dentro: ojalá que no gane, porque no quería que se recuerde a los chicos de ese modo" (Entrevista personal, junio de 2015)

Jelin y Langland (2003) se preguntan si existe una estética más apropiada que otras para mantener la memoria del horror; se interrogan igualmente sobre cómo representar a los desaparecidos o quiénes van a decidir la manera en que estas cuestiones se plasmaran materialmente. Para el caso del Monumento de la Masacre de Floresta vimos que los familiares rechazaron el primer proyecto presentado a la Asamblea porque "no les gustó", y en el testimonio anterior vemos las dificultades de representar materialmente a las víctimas. Finalmente, el premio le correspondió al proyecto Monumento-Homenaje "Los chicos de Floresta-Sucesos 2001". El grupo escultórico mostraba a una mujer arrodillada y por detrás tres figuras humanas de pie, todos rodeados por sólidos bloques cerámicos. Las dos madres de las víctimas se mostraron muy conformes con la decisión del jurado.

\subsection{El monumento Chicos de Floresta, ¿una obra de arte o un "objeto de disputa"?}

Inmediatamente después del concurso apareció el problema de la construcción y del emplazamiento de la obra, dado las importantes dimensiones de la obra escultórica se presentó rápidamente la pregunta: "¿dónde lo vamos a hacer?". A partir de aquí ingresaron en escena los agentes estatales que permitieron que el proyecto se concretara. El director del Centro de Formación Profesional del barrio ofreció los talleres para que las escultoras pudieran trabajar, los alumnos del Centro participaron de las tareas de construcción como parte de la capacitación profesional. Para insertar la construcción del monumento dentro de las instalaciones del Centro fueron necesarias, según las palabras de una de las escultoras, algunas modificaciones como "mejorar el cielorraso del taller para instalar un aparejo para 
levantar $2.000 \mathrm{~kg}$ ". Además se modificó el proyecto pedagógico para incluir los cursos de Cerámica y de Herrería y Soldadura para facilitar la incorporación de los alumnos a la construcción del proyecto. El director de Infraestructura Escolar facilitó los materiales y las herramientas para el nuevo taller. El hecho de que ambos directores fueran vecinos del barrio de Floresta parece haber facilitado todo el proceso de construcción del monumento, allanándose con bastante facilidad los innumerables problemas que se presentaban a diario.

La construcción del monumento estuvo a cargo del área de educación de Ciudad Autónoma de Buenos Aires, mientras que gestionar su emplazamiento en el espacio público y organizar el acto de inauguración estuvo a cargo de la Secretaría de Derechos Humanos tanto de la Ciudad de Buenos Aires como de la Nación. En este sentido, las escultoras manifestaron haber recibido un amplio apoyo de parte de los funcionarios de ambas agencias estatales. Ellas, como artistas periféricas, esperaban el reconocimiento de quienes podian consagrarlas como escultoras. Sin embargo, las artistas enfatizaron que la Secretaría de Cultura "nunca estuvo presente". Esta ausencia perturbó el proceso de creación de las artistas, mientras recibían el acompañamiento de muchos sectores como el periodismo, los movimientos barriales, los agentes estatales de las secretarías de educación y de derechos humanos, sus pares de cultura ignoraban su obra. Las escultoras se preguntaban: "¿será fea, no les gusta? ¿por qué la ignoran los artistas?".

La gestión del emplazamiento la llevó adelante una diputada vinculada a la Asamblea de Floresta. Apenas unos meses antes de finalizar la construcción de la obra escultórica, la legislatura porteña dio curso al expediente que autorizaba el emplazamiento en el espacio público. El cuerpo del documento daba cuenta de que el concurso de adjudicación de la obra había contado con el aval y el auspicio de la Secretaría de Derechos Humanos de la Nación, y de la Dirección de Derechos Humanos del Gobierno de la Ciudad ${ }^{21}$. El 9 de agosto de 2004 se realizó la Audiencia Pública en la que se expusieron los testimonios de los familiares de las víctimas, de vecinos, asambleístas y escultoras que fundamentaron el tratamiento de la ley de emplazamiento. Dentro de

\footnotetext{
${ }^{21}$ Disponible en: www.legislatura.gov.ar/legislatura/316/imagenes/0810d2004.doc. Última consulta: 03/06/2015.
} 
los diversos posicionamientos a favor del monumento es relevante el de una de las asambleístas:
(...) Tengo un registro (...) que viene realizando la Correpi sobre muertes de personas a manos de las fuerzas de seguridad y armadas. (...) incluyen casos (...) en los cuales los homicidas eran miembros de agencias represivas del Estado: Policía Federal, policía provincial, Gendarmería, Prefectura, servicios penitenciarios o fuerzas armadas (...) Hasta hoy, el registro desde el año 1983 es de 1.508 casos. $^{22}$

Con este discurso la asambleísta incluyó a las víctimas de la Masacre de Floresta en el universo de las víctimas de "gatillo fácil". Finalmente, el 26 de agosto de 2004 se sancionó por unanimidad la Ley $N^{\circ} 1440$ por la que se autorizaba el emplazamiento en el espacio público del monumento "Chicos de Floresta-Sucesos 2001". Alli se mostraba que todo el proceso de creación y gestión de la ley fue acompañado por representantes de organismos de Derechos Humanos que fueron ligando la Masacre de Floresta a la causa contra los represores de la dictadura reciente, y desde esta por medio de un salto temporal a la causa de las víctimas de "gatillo fácil". Mientras esto sucedía a nivel de las secretarias estatales y de los organismos de Derechos Humanos, los familiares de las víctimas de la Masacre de Floresta se manifestaban en las cuatro marchas multitudinarias que se hicieron en 2004 en la Ciudad Autónoma de Buenos Aires en contra de las muertes de jóvenes por la inseguridad. Y así se incorporaban a una causa más general: las víctimas en democracia por inseguridad y violencia institucional.

¿De qué manera comprender que desde el concurso de adjudicación de la obra hasta su emplazamiento el proceso estuvo dominado por militantes de organizaciones y actores de agencias estatales ambos de derechos humanos, mientras que los actores ligados al arte se limitaron al jurado y a las escultoras? Para Ana Gugliemucci los monumentos pueden pensarse como "espacios-objeto" que condensan el poder de nombrar el pasado y crear relaciones sociales en el presente. Y por ese poder de articular pasado, presente y futuro por medio de la materialidad los monumentos son "objeto de disputa" (Gugliemucci, 2011).

\footnotetext{
${ }^{22}$ Fragmento del Sumario de la Audiencia Pública en la Legislatura de la Ciudad Autónoma de Buenos Aires. Documento proporcionado por la asambleista Anahí Aizpuru. Resaltado de la autora.
} 
Pero, ¿quiénes estaban en disputa? Con la llegada del nuevo siglo comenzó a gestarse una política estatal de la memoria que representaba principalmente a las víctimas del terrorismo de Estado, que además fue acompañada por un movimiento de derechos humanos que bregó por la "institucionalización de la memoria" (Da Silva Catela, 2011). Familiares, compañeros y demás allegados a los detenidos desaparecidos pasaron a disputar una "memoria dominante" (ibídem). Asimismo, para Jelin y Langland (2003) el proceso de creación y construcción de un monumento como "lugar de memoria" implica la transmisión de un mensaje. En este sentido, para una de sus creadoras, la obra escultórica "dialoga, recuerda y conmueve el dolor, la fuerza de la unión y la memoria de los sucesos inescrupulosos que no tienen que volver a ocurrir". Claramente, el mensaje a difundir era el de la causa de las víctimas del terrorismo de Estado. Sin embargo, el monumento se realizó en homenaje a tres jóvenes muertos en la Masacre de Floresta cuyos familiares bregaban por instalar en la escena pública la causa de las víctimas en democracia y lograr su reconocimiento por parte del Estado.

\subsection{El monumento}

Figura 1. Monumento-Homenaje "Los chicos de Floresta-Sucesos 2001"

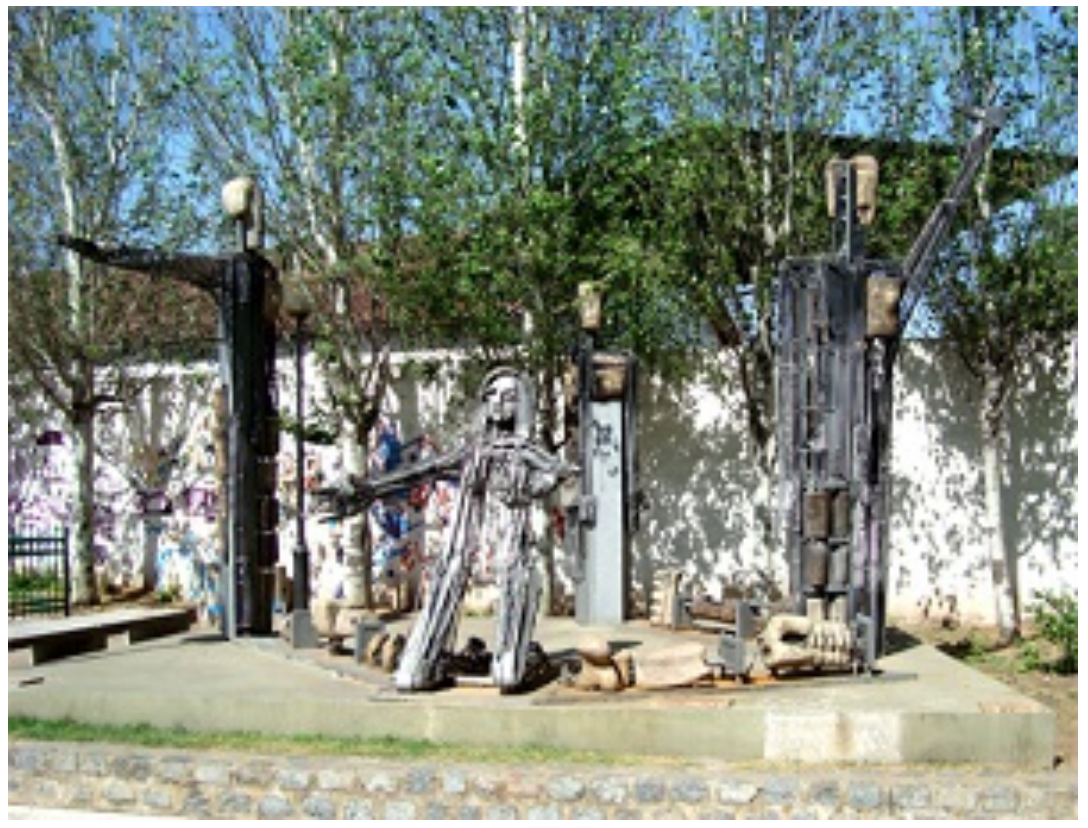

Fuente: www.kuwotoceramicas.com 
El 29 de noviembre de 2004 fue inaugurado el monumento "Los Chicos de Floresta-Sucesos de 2001". El día del acto inaugural fue notable la presencia de los funcionarios estatales que representaban al gobierno nacional y a las secretarías de Derechos Humanos de Nación y de la Ciudad de Buenos Aires ratificando la hegemonía de ese campo en todo el proceso de construcción y emplazamiento de la obra escultórica. Siguiendo la memoria descriptiva del monumento, facilitada por las escultoras, vemos que para la construcción de las estructuras se utilizó hierro que les otorgó la necesaria "resistencia a la intemperie una cualidad que nos habla de esa resistencia que ofrece la vida ante la muerte". Además, la fortaleza del hierro se combinó con la calidez de la cerámica que le otorgó corporeidad. Las tres figuras de pie representaban a los jóvenes asesinados, y fueron "resueltas dentro de un planteo abstracto, totémico", sus rostros fueron apenas esbozados ya que, según la memoria, "no hay retratos posibles, en ellos están representados todos los jóvenes que mueren en nuestro país por la violencia institucional y militar". Así vemos que desde su concepción el monumento transmitía el mensaje de las víctimas de terrorismo de Estado y de las víctimas en democracia.

Durante el desarrollo del concurso la madre de una de las víctimas "miraba las maquetas y ninguna [le] gustaba, una era muertos amontonados en una gran pila, los muertos de la dictadura y arriba los de la Masacre, nuestros hijos" (Entrevista personal, junio 2015). Finalmente, la obra ganadora representó a los tres jóvenes de pie y a una mujer arrodillada. Cuando se consultó a la madre de una de las víctimas acerca de la figura femenina contestó: "me veo pariendo". Cuando le preguntaron cuál era su hijo entre las tres figuras de pie en el monumento, ella respondió: "él del brazo levantado, Maxi era así de empujar e ir al frente". Que las víctimas hayan sido representadas de pie y con una actitud luchadora frente a la vida fue una manera de "restitución de la humanidad" para quienes murieron como animales (Pita, 2010: 116). Los muertos no eran animales, eran seres humanos con una personalidad y un carácter que los distinguía, y con familiares y vecinos que habian denunciado y pedido justicia por ellos.

Jelin y Langland (2003) plantean que hay luchas por el poder "estético" entre emprendedores de los proyectos: familiares de víctimas y activistas del movimiento de derechos humanos, los expertos y la acción gubernamental. Podemos pensar que las madres de las víctimas 
lograron ganar la batalla por la estética; las figuras de la madre arrodillada pariendo y los hijos de pie con una actitud luchadora frente a la vida le otorgaba a las víctimas mayor dignidad en contraposición a aquella maqueta que representaba la tragedia con muertos amontonados en una gran pila. La tarea, por parte de los familiares, de humanizar a los jóvenes "muertos y arrastrados como perros" estaba cumplida.

Figura 2. Plaqueta al pie del monumento-homenaje "Los chicos de Floresta-Sucesos 2001"

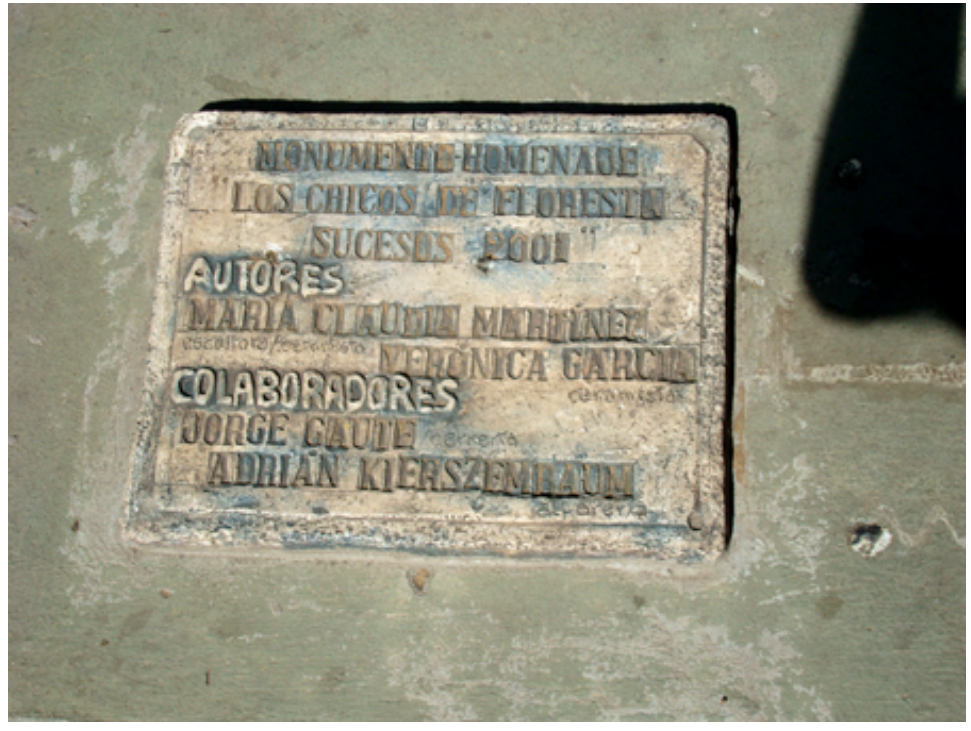

Fuente: www.mundofloresta.com/elbarrio/

Como se puede ver en el grupo escultórico, las víctimas de Floresta ocupan un lugar protagónico en la escena representada. Estas víctimas eclipsaron a aquellas otras víctimas de la represión estatal en 2001, relegándolas al lugar oculto y periférico de una referencia en una placa: "Sucesos 2001". Mientras que las víctimas de terrorismo de Estado, representadas por sólidos bloques de piedra, rodeaban la obra, a sus pies, "sugiriendo el pasado, los restos orgánicos de los que nos antecedieron para forjar nuestro país" 23 . Así vemos que en su lugar de origen, la Argentina, la figura del detenido desaparecido fue representada en el monumento a la Masacre de Floresta como un objeto rocoso que viaja en el tiempo impasible e inmutable, "siempre igual por

\footnotetext{
${ }^{23}$ Fragmento extraído de un folleto gráfico que circuló en el barrio en el año 2004 durante la ejecución de la obra escultórica.
} 
mucho que se desplace" tal cual describe Gabriel Gatti al "desaparecido transnacional" (2011:521).

Figura 3. Formas escultóricas representando a las víctimas de terrorismo de Estado en torno al monumento-homenaje "Los chicos de Floresta-Sucesos 2001"

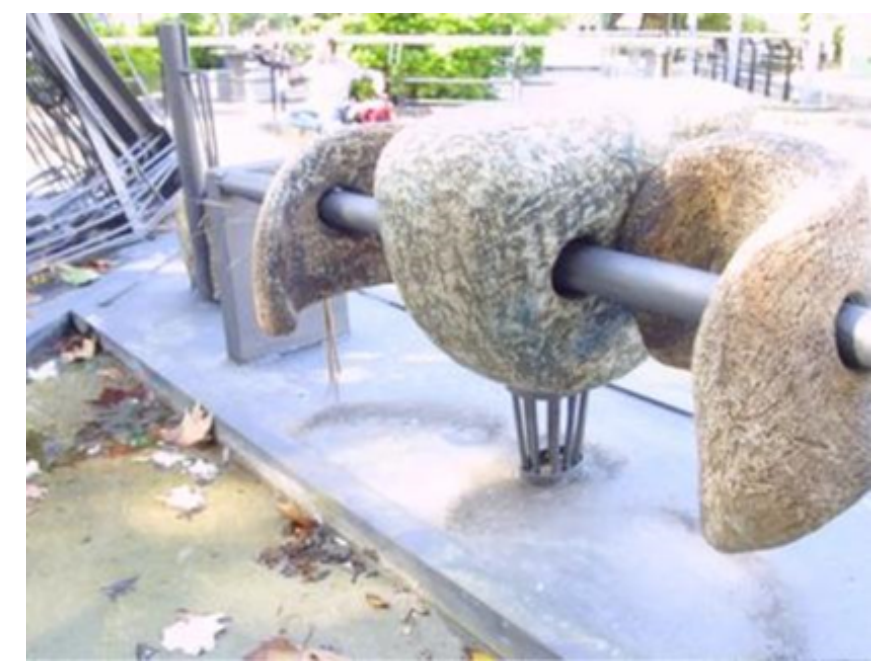

Fuente: www.kuwotoceramicas.com

La propuesta de Gatti (ibídem) da cuenta del marco interpretativo en que fermenta la figura del detenido desaparecido en las dictaduras de la década de 1970 en América Latina y que ha servido para entender lo ocurrido en otras dictaduras en el mundo. Ese marco interpretativo también sirve para clasificar casos de víctimas de "gatillo fácil" de la historia reciente de la Argentina, y asociarlos al mantenimiento de prácticas represivas del terrorismo de Estado por parte de agentes de seguridad estatales.

Diez años más tarde, en 2014, al momento de la restauración del monumento, éste fue resignificado en el discurso de una de las escultoras: "esa mujer que arrodillada mide $2,20 \mathrm{~m}$, si se pusiera de pie mediría 4 o casi $5 \mathrm{~m}$. Hoy estamos de pie" (Entrevista personal, julio de 2015). La escultora hacía alusión a la superación de la crisis del año 2001. Consultada la escultora sobre este cambio de significación contestó: "la mujer arrodillada es la Patria" (Entrevista personal, julio de 2015). De modo que no puede verse al monumento como un mensaje unívoco y consensuado sino como un escenario en el que se despliegan luchas de sentido entre diferentes "nosotros" (Jelin y Langland, 2003). 


\section{CiERRE}

En el monumento-homenaje "Chicos de Floresta-Sucesos 2001" se reúnen las víctimas del terrorismo de Estado, las víctimas de represión estatal de los hechos del 19 y 20 de diciembre de 2001 y las víctimas de la Masacre de Floresta. Claramente, en este escenario las luchas de sentido entre diferentes "nosotros" están a la vista, no se trata de diferencias que haya que rastrear al interior de una categoría sino de luchas públicamente expuestas entre víctimas generadas en "contextos de experiencia" históricamente distantes. Entonces, ¿cómo fue posible tal reunión?, ¿qué elementos intervinieron para lograr la congregación en un mismo "lugar de memoria" de víctimas jerárquicamente diferentes y cuyos familiares tienen visiones distintas sobre el pasado reciente? Dar respuesta a este interrogante fue posible por medio de un trabajo de campo que posibilitó conocer las posiciones de los distintos actores involucrados en la construcción de la obra escultórica. El análisis comparativo entre los casos acá expuestos y, apoyándome en trabajos de otros autores sobre otros casos, se pudo establecer diferencias y similitudes en las posiciones que cada uno de los actores ocupaba en el campo de las víctimas.

El trabajo argumenta que la confluencia de víctimas generadas en contextos históricos diferentes y que interpelaban al Estado desde causas disímiles en un mismo monumento-homenaje es comprensible si situamos la represión estatal del gobierno dictatorial de la década de 1970 como el marco interpretativo. Se pudo ver que el trazado de una línea temporal sin discontinuidades ni rupturas logro unir víctimas del terrorismo de Estado, ya consagradas, con víctimas de represión estatal durante la crisis del 2001, y con víctimas de "gatillo fácil" en un período democrático que buscaban reconocimiento estatal como víctimas de la inseguridad. Pero, la represión estatal por sí sola no explica que luchas pasadas y presentes se hayan integrado en una obra escultórica. Indagar sobre el proceso de creación, de gestión, de construcción y de emplazamiento del monumento permitió establecer la prevalencia de un mundo de agentes y relaciones muy comprometido con la transmisión de "la memoria dominante" de las víctimas del terrorismo de Estado promovida, además, desde una política estatal de Derechos Humanos. Mientras las víctimas en democracia se manifestaban en las calles pidiendo el reconocimiento estatal, ¿se hubiera construido el monumento- homenaje a las víctimas de Floresta en tanto víctimas de 
"gatillo fácil" en democracia? Podemos pensar que esa construcción solo fue posible entendiendo a las víctimas de Floresta como transmisoras del mensaje de las víctimas de terrorismo de Estado, dejando asi opacado el reclamo de las víctimas en democracia.

\section{BibLiOgRAFÍA}

Agier, M. (2008). Gérer les indésirables. Des camps des réfugiés au gouvernement humanitaire. Paris: Flammarion.

Boltanski, L. (1990). El Amor y la Justicia como competencias. Tres ensayos de sociología de la acción. Buenos Aires: Amorrortu editores.

Catoggio, M. S. (2011). Mártires y sobrevivientes: figuras de la violencia política en los años sesenta y setenta. Lucha armada en la Argentina, Anuario, 100-110.

Cefaï, D. (2011). Diez propuestas para el estudio de las movilizaciones colectivas. De la experiencia al compromiso. Revista de Sociología, 26, 137-166.

Da Silva Catela, L. (2011). Pasados en conflicto. De memorias dominantes, subterráneas y denegadas. En Bohoslavsky, E. et al. (Comps.), Problemas de Historia Reciente del Cono Sur, vol. 1, 99-124, Buenos Aires: UNGS- Prometeo Libros.

Da Silva Catela, L. (2014). Lo que merece ser recordado... Conflictos y tensiones en torno a los proyectos públicos sobre los usos del pasado en los sitios de memoria. Clepsidra. Revista Interdisciplinaria de Estudios sobre Memoria, 2, 28-47.

Gatti, G. (2011). De un continente a otro: el desaparecido transnacional, la cultura humanitaria y las víctimas totales en tiempo de guerra global. Politica y Sociedad, 48(3), 519-536.

Gaxie, D. (2004). La democracia representativa. Santiago de Chile: LOM Ediciones

Gugliemucci, A. (2011). La construcción social de los espacios para la memoria sobre el terrorismo de Estado en Argentina como lugares de memoria auténtica. Sociedad e Cultura, 14(2), 321-332.

Jelin, E., \& Langland, V. (2003). Las marcas territoriales como nexo entre pasado y presente. En Monumentos, memoriales y marcas territoriales, 5-11, Madrid: Siglo Veintiuno.

Pita, M. V. (2010). Formas de morir y formas de vivir. El activismo contra la violencia policial. Buenos Aires: Editores del Puerto S.R.L. 
Rebollar, A. I. (2014). Mucho más que lazos de sangre y dolor: el activismo por las víctimas en democracia en la Asociación Madres del Dolor. Tesis de graduación inédita. San Martín: Universidad Nacional de San Martín.

Rebollar, A. I. (2016). De accidente a responsabilidad política, la construcción de una denuncia pública. El caso Marcela Iglesias en el Parque 3 de Febrero (CABA). Publicar en Antropología y Ciencias Sociales, $X I V(X X)$, 73-97. ppct.caicyt.gov.ar/index.php/publicar/article/viewFile/8171/8497.

Sampaolo, M. (2009). El Corralón. In VV.AA., Los lugares de la memoria (pp. 14-22). Buenos Aires: Editorial Madreselva.

Schuster, et al. (2002). La trama de la crisis. Modos y formas de protesta social a partir de los acontecimientos de diciembre de 2001. Informes de Coyuntura, 3, Buenos Aires: Instituto Gino Germani, Universidad de Buenos Aires. http://biblioteca.clacso.edu.ar/Argentina/iigguba/20100323081642/IC3.pdf.

Tejerina, B. (2010). La sociedad imaginada. Movimientos sociales y cambio cultural en España. Madrid: Editorial Trotta.

Vecchioli, V. (2013). Las víctimas del Terrorismo de Estado y la gestión del pasado reciente en la Argentina. Papeles del CEIC, 2013/1(90), CEIC (Centro de Estudios sobre la Identidad Colectiva), Universidad del País Vasco, http://www.identidadcolectiva.es/pdf/90.pdf.

Vecchioli, V. (2014a). Víctima. In G. Vommaro \& A. Adelstein (Eds.). Diccionario del léxico corriente de la política argentina. Palabras en democracia (1983-2013), 358-361, Buenos Aires: Universidad Nacional de General Sarmiento

Vecchioli, V. (2014b). La monumentalización de la ciudad: los sitios de memoria como espacios de intervención experta de los hacedores de ciudad. Revista de Estudios Sociales Contemporáneos, 10, 33-44, http://bdigital.uncu.edu.ar/6429.

Vecchioli, V. (2014c). La recreación de una comunidad moral y la institución de un relato legítimo sobre los derechos humanos en la Argentina. Revista Publicar, XII(XVII), diciembre, (pp.67-93).

Verdery, K. (1999). Giving proper burial, reconfiguring space and time. In The political lives of dead bodies: reburial and Postsocialist Change (pp. 95-127). Nueva York: Columbia University Press

Zenobi, D. (2014). Familia, política y emociones. Las víctimas de Cromañon entre el movimiento y el Estado. Buenos Aires: Editorial Antropofagia. 